\title{
Antimony-doped Tin(II) Sulfide Thin Films
}

\section{Citation}

Sinsermsuksakul, Prasert, Rupak Chakraborty, Sang Bok Kim, Steven M. Heald, Tonio Buonassisi, and Roy G. Gordon. Forthcoming. Antimony-doped tin(II) sulfide thin films. Chemistry of Materials.

\section{Published Version}

doi: $10.1021 / \mathrm{cm} 3024988$

\section{Permanent link}

http://nrs.harvard.edu/urn-3:HUL.InstRepos:10021411

\section{Terms of Use}

This article was downloaded from Harvard University's DASH repository, and is made available under the terms and conditions applicable to Open Access Policy Articles, as set forth at http:// nrs.harvard.edu/urn-3:HUL.InstRepos:dash.current.terms-of-use\#OAP

\section{Share Your Story}

The Harvard community has made this article openly available.

Please share how this access benefits you. Submit a story.

Accessibility 


\title{
Antimony-doped Tin(II) Sulfide Thin Films
}

\author{
Prasert Sinsermsuksakul, ${ }^{\dagger}$ Rupak Chakraborty, ${ }^{\ddagger}$ Sang Bok Kim, ${ }^{\dagger}$ Steven M. Heald, ${ }^{\S}$ Tonio Buonassisi, ${ }^{\ddagger}$ \\ Roy G. Gordon*,† \\ †Department of Chemistry and Chemical Biology, Harvard University, Cambridge, MA 02138, United States \\ ${ }^{\ddagger}$ Department of Mechanical Engineering, Massachusetts Institute of Technology, Cambridge, MA 02139, United States \\ ${ }^{\S}$ Advanced Photon Source, Argonne National Laboratory, Argonne, IL 60439, United States
}

KEYWORDS: thin films, doping, semiconductor, tin sulfide, antimony.

Supporting Information Placeholder

\begin{abstract}
Thin-film solar cells made from earth-abundant, inexpensive, and non-toxic materials are needed to replace the current technologies whose widespread use is limited by their use of scarce, costly, and toxic elements. ${ }^{1}$ Tin monosulfide (SnS) is a promising candidate for making absorber layers in scalable, inexpensive, and non-toxic solar cells. SnS has always been observed to be a $p$-type semiconductor. Doping SnS to form an n-type semiconductor would permit the construction of solar cells with p-n homojunctions. This paper reports doping SnS films with antimony, a potential $n$-type dopant. Small amounts of antimony $(\sim 1 \%)$ were found to greatly increase the electrical resistance of the $\mathrm{SnS}$. The resulting intrinsic $\mathrm{SnS}(\mathrm{Sb})$ films could be used for the insulating layer in a p-i-n design for solar cells. Higher concentrations ( $\sim 5 \%$ ) of antimony did not convert the $\mathrm{SnS}(\mathrm{Sb})$ to low-resistivity $n$-type conductivity, but instead the films retain such a high resistance that the conductivity type could not be determined. Extended X-ray absorption fine structure analysis reveals that the highly doped films contain precipitates of a secondary phase that has chemical bonds characteristic of metallic antimony, rather than the antimony-sulfur bonds found in films with lower concentrations of antimony.
\end{abstract}

\section{Introduction}

In the past few decades, tin(II) sulfide (SnS) has gained much attention as a possible alternative absorber material for the next generation of thin-film solar cells to replace the current bestdeveloped technology based on $\mathrm{Cu}(\mathrm{In}, \mathrm{Ga}) \mathrm{Se}_{2}$ and $\mathrm{CdTe}$, which involve toxic $\mathrm{Cd}$ and rare elements $\mathrm{In}, \mathrm{Ga}$, and Te. In addition to low toxicity, low cost, and natural abundance of its constituent elements, SnS has high optical absorption $\left(\alpha>10^{4} \mathrm{~cm}^{-1}\right)$ above the direct absorption edge at $1.3-1.5 \mathrm{eV},{ }^{2,3}$ It has native $p$ type conduction due to the small enthalpy of formation of tin vacancies, which generate shallow acceptors. ${ }^{4} \quad$ SnS-based heterojunction solar cells have been reported using different $n$ type partners such as $\mathrm{ZnO},{ }^{5} \mathrm{CdS},{ }^{6} \mathrm{Cd}_{1-x} \mathrm{Zn}_{x} \mathrm{~S},{ }^{7} \mathrm{SnS}_{2},{ }^{8} \mathrm{TiO}_{2},{ }^{9}$ and $a-S_{i}{ }^{10}$ The power conversion efficiencies $(\eta)$ achieved so far on these planar heterojunction devices are still rather low $(<$ $1.3 \%)^{6}$ Some of the main contributors to this poor efficiency could be an unfavorable band offset and rapid carrier recombination at trap states near the interface between $\mathrm{SnS}$ and the $n$ type buffer layers. ${ }^{11}$ In this aspect, a homojunction might provide a better device performance, provided that $n$-type $\mathrm{SnS}$ can be produced. In addition to the homojunction approach, improved SnS-based solar cells might have a $p-i(\mathrm{SnS})_{-n}$ structure, similar to a strategy proposed by Sites et al. for CdTe. ${ }^{12}$ This approach requires $\mathrm{SnS}$ to have a low carrier concentration on the order of $10^{13} \mathrm{~cm}^{-3}$, which is lower than typical undoped SnS values of $10^{15}-10^{18} \mathrm{~cm}^{-3}$. 3, 4, 6, 13 Therefore, the ability to control carrier concentration and conduction type of $\mathrm{SnS}$ could improve SnS-based thin film solar cells and, in general, could broaden the utility of $\mathrm{SnS}$ as an optoelectronic semiconductor outside the field of photovoltaics.

SnS can be doped by $\mathrm{Ag}^{13,14}$ and $\mathrm{Cu}^{15}$ to increase its hole concentration to around $10^{19} \mathrm{~cm}^{-3}$. Dussan et al. attempted to use $\mathrm{Bi}$ to substitute $\mathrm{Sn}$ in $\mathrm{SnS}$ to provide $n$-type conduction, but the material remains p-type below $50 \% \mathrm{Bi}$ concentration. ${ }^{16}$ Sajeesh et al. reported $n$-type $\mathrm{SnS}$ thin films obtained by chemical spray pyrolysis, but this result is probably due to a significant n-type $\mathrm{Sn}_{2} \mathrm{~S}_{3}$ impurity phase in the films. ${ }^{17}$ One promising $n$-type substitutional dopant is antimony(III), $\mathrm{Sb}^{3+}$, due to the similarity of its ionic radius to $\mathrm{Sn}^{2+}$. Albers et al. reported the use of $\mathrm{Sb}$ as a dopant that lowers the hole concentration of $\mathrm{SnS}$ to be less than $10^{14} \mathrm{~cm}^{-3} \cdot{ }^{13}$ Nonetheless, the specific Sb concentration and detailed studies of its effect on the electrical properties of SnS were not reported. By increasing the $\mathrm{Sb}$ concentration further, it might be possible to convert $\mathrm{SnS}$ to an $n$-type semiconductor. Here, we report the preparation of Sb-doped SnS thin films, $\mathrm{SnS}(\mathrm{Sb})$, from the reaction of bis(N,N'-diisopropylacetamidinato)tin(II) $\left[\mathrm{Sn}\left(\mathrm{MeC}(\mathrm{N}-i \mathrm{Pr})_{2}\right)_{2}\right]$ and tris(dimethylamido)antimony(III) $\left[\mathrm{Sb}\left(\mathrm{NMe}_{2}\right)_{3}\right]$ with hydrogen sulfide $\left(\mathrm{H}_{2} \mathrm{~S}\right)$. We identify the dopant chemical state, and report the effect of $\mathrm{Sb}$ dopant concentration on the crystal structure and electrical properties of the material.

\section{Experiment}

Sb-doped SnS thin film. Pure, stoichiometric, single-phase SnS thin films can be obtained by atomic layer deposition 
(ALD) from the reaction of bis(N,N'-diisopropylacetamidinato)tin(II) $\left[\mathrm{Sn}\left(\mathrm{MeC}(\mathrm{N}-i \mathrm{Pr})_{2}\right)_{2}\right.$, referred here as $\left.\mathrm{Sn}(\mathrm{amd})_{2}\right]$ and hydrogen sulfide $\left(\mathrm{H}_{2} \mathrm{~S}\right){ }^{3}$ Rather than using ALD as previously reported, ${ }^{3}$ SnS thin films were deposited using a modified chemical vapor deposition (CVD) process, referred here as a pulsedCVD, to speed up the deposit rate to $\sim 15$ times higher than that of ALD. The sequence of one cycle of a pulsed-CVD is composed of (i) injection of $\mathrm{Sn}(\mathrm{amd})_{2}$ vapor using $\mathrm{N}_{2}$ assistance, (ii) injection of $\mathrm{H}_{2} \mathrm{~S}$ gas to mix and react with the $\mathrm{Sn}(\mathrm{amd})_{2}$ vapor trapped inside the deposition zone, and (iii) evacuation of the gas mixture and by-products. Unlike conventional ALD, there is no purging of excess $\mathrm{Sn}(\mathrm{amd})_{2}$ before $\mathrm{H}_{2} \mathrm{~S}$ injection, thereby increasing the deposition rate at the cost of some nonuniformity in the film thickness along the length of the reactor. The substrate temperature was set to $200{ }^{\circ} \mathrm{C}$. The tin precursor source was kept at $95{ }^{\circ} \mathrm{C}$. A gas mixture of $4 \% \mathrm{H}_{2} \mathrm{~S}$ in $\mathrm{N}_{2}$ (Airgas Inc.) was used as the source of sulfur. $\mathrm{H}_{2} \mathrm{~S}$ is a toxic, corrosive, and flammable gas (lower flammable limit of $4 \%$ ). ${ }^{18}$ Thus, it should be handled with caution. An appropriate reactor design for $\mathrm{H}_{2} \mathrm{~S}$ compatibility can be found elsewhere. ${ }^{19}$ The partial pressures of $\mathrm{Sn}(\mathrm{amd})_{2}$ and $\mathrm{H}_{2} \mathrm{~S}$ after injecting into the deposition zone for each pulsed-CVD cycle are approximately 100 mTorr and $240 \mathrm{mTorr}$, respectively.

$\mathrm{Sb}_{2} \mathrm{~S}_{3}$ thin films can be prepared from ALD using the reaction of tris(dimethylamido)antimony(III) [Sb(NMe $\left.)_{3}\right]$ (SigmaAldrich) and hydrogen sulfide $\left(\mathrm{H}_{2} \mathrm{~S}\right){ }^{20}$ The stop-flow ALD mode $^{21,22}$ was used for the deposition. The antimony source was kept at room temperature $\left(25^{\circ} \mathrm{C}\right)$. The total exposure of $\mathrm{Sb}\left(\mathrm{NMe}_{2}\right)_{3}$ and $\mathrm{H}_{2} \mathrm{~S}$ for each of an ALD cycle were approximately 0.7 and 1.1 Torr $s$, respectively. Sb-doped SnS thin films were deposited by inserting cycles of $\mathrm{ALD} \mathrm{Sb}_{2} \mathrm{~S}_{3}$ into the deposition of $\mathrm{SnS}$. By varying the ratio between the numbers of $\mathrm{Sb}_{2} \mathrm{~S}_{3}$ and $\mathrm{SnS}$ cycles, controlled concentrations of $\mathrm{Sb}^{3+}$ in $\mathrm{SnS}$ can be obtained. For example, a $1 \%$ cycle ratio film, $\mathrm{SnS}(1 \% \mathrm{Sb})$, was prepared by alternating between 99 cycles of $\mathrm{SnS}$ and 1 cycle of $\mathrm{Sb}_{2} \mathrm{~S}_{3}$. Three samples were deposited using $1 \%, 2 \%$, and $5 \% \mathrm{Sb}$ cycles to determine the effect of $\mathrm{Sb}$ concentration on the crystal structure and electrical properties of the films.

Material Characterization. Film morphology was characterized using field-emission scanning electron microscopy (FESEM, Zeiss, Ultra-55). The film thickness was determined from cross-sectional SEM. The elemental composition of the films was determined by Rutherford backscattering spectroscopy (RBS, Ionex 1.7 MV Tandetron) and time-of-flight secondary ion mass spectroscopy (ToF-SIMS). X-ray photoelectron spectroscopy (XPS, Surface Science, SSX-100) was used to detect possible carbon, nitrogen, and oxygen contamination in the films. The crystal structures of $\mathrm{SnS}$ and Sb-doped $\mathrm{SnS}$ thin films were examined by X-ray diffraction (XRD, PANalytical X'Pert Pro) with $\mathrm{Cu} \mathrm{K} \alpha$ radiation $(\lambda=1.542 \AA$ ) using $\theta-2 \theta$ scan. The lattice parameters were calculated from least square fitting to the position of the Bragg peaks determined by Gaussian fit. Electrical properties of the films were characterized by Hall measurement (MMR technologies K2500) using the Van der Pauw method at $300 \mathrm{~K}$. Synchrotron-based extended X-ray absorption fine structure (EXAFS) was used to study the local atomic environment of the antimony dopant. Synchrotron measurements were conducted at beamline 20-BM at the $\mathrm{Ad}$ vanced Photon Source of Argonne National Laboratory. ${ }^{23}$

\section{Results and Discussion}
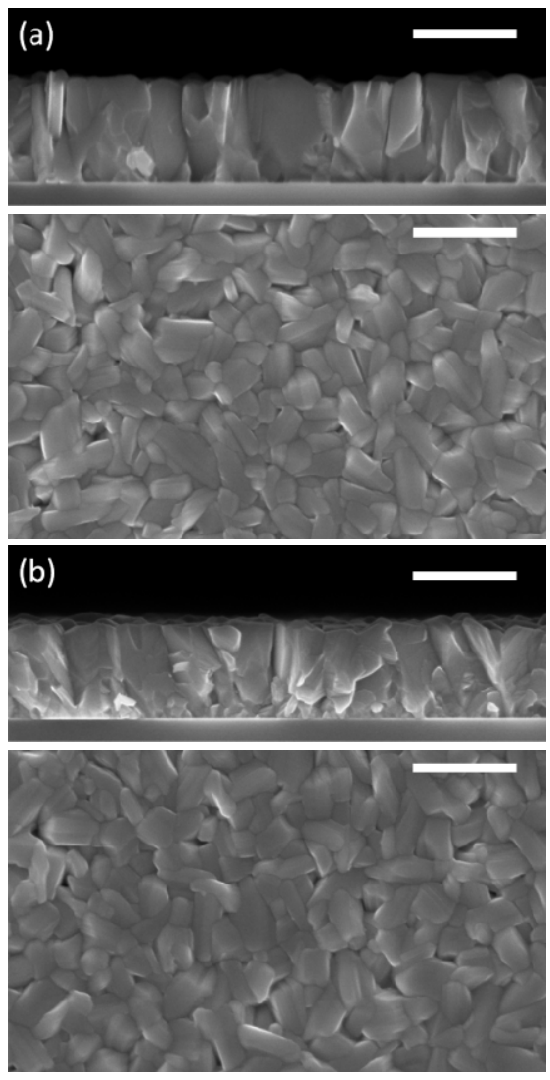

Figure 1. Cross-sectional and plan-viewed SEM images of (a) an undoped SnS film and (b) a SnS(5\% Sb) film. The scale bar is 500 $\mathrm{nm}$.

The obtained SnS and Sb-doped SnS films appeared smooth, pin-hole free, and adhere well to the substrate $\left(a-\mathrm{SiO}_{2}\right)$. Figure 1 shows the surface morphology of an undoped SnS film and a $\mathrm{SnS}(5 \% \mathrm{Sb})$ film grown by pulsed-CVD at $200{ }^{\circ} \mathrm{C}$, as observed by SEM. Because of the low level of doping, the surface morphology of undoped SnS and all of the Sb-doped SnS samples are not significantly different. The film thicknesses of all the samples are approximately $500 \mathrm{~nm}$, as determined from crosssectional SEM. The chemical composition of the undoped SnS film was measured using RBS to be stoichiometric $\mathrm{SnS}$ to within the detection limit $( \pm 1 \%)$. As in ALD SnS ${ }^{3}$ and $\operatorname{ALD~} \mathrm{Sb}_{2} \mathrm{~S}_{3},{ }^{20}$ XPS does not detect any carbon or nitrogen contamination in the Sb-doped SnS films deposited at this particular temperature.

The atomic concentration of $\mathrm{Sb}$ in $\mathrm{SnS}$ was estimated by ToF-SIMS (Figure 2a) from the average intensity of $\mathrm{Sb}^{+}$and $\mathrm{Sn}^{+}$ using a Cs ${ }^{+}$sputter source. If the efficiencies of generating $\mathrm{Sb}^{+}$ and $\mathrm{Sn}^{+}$ions are assumed to be the same, then the $\mathrm{Sb}$ concentrations in $\mathrm{SnS}(1 \% \mathrm{Sb}), \mathrm{SnS}(2 \% \mathrm{Sb})$, and $\mathrm{SnS}(5 \% \mathrm{Sb})$ are determined to be $0.7 \pm 0.2 \%, 1.2 \pm 0.3 \%$, and $4.5 \pm 0.3 \%$, respectively. Because we lack absolute concentration standards for SIMS analysis of dilute $\mathrm{Sb}$ in $\mathrm{Sn}$, these concentrations could be in error by a constant calibration factor. Because of the chemical similarity of tin and antimony metals, it is expected that the calibration factor should not deviate significantly from unity. 
Table 1. Summary of Sb concentrations, lattice constants, and electrical properties of undoped and Sb-doped SnS films.

\begin{tabular}{ccccccccc}
\hline \multirow{2}{*}{ sample } & $\begin{array}{c}\text { cycle ratio } \\
\text { Sn:Sb }\end{array}$ & $\begin{array}{c}\text { \%Sb in } \\
\text { SnS }\end{array}$ & \multicolumn{3}{c}{ lattice constant $(\AA)$} & $\begin{array}{c}\text { resistivity } \\
(\Omega \mathrm{cm})\end{array}$ & $\begin{array}{c}\text { carrier density } \\
\left(\mathrm{cm}^{-3}\right)\end{array}$ & $\begin{array}{c}\text { mobility } \\
\left(\mathrm{cm} / \mathrm{Vs}^{2}\right)\end{array}$ \\
\hline SnS & $1: 0$ & 0 & $4.30 \pm 0.01$ & $11.19 \pm 0.02$ & $3.99 \pm 0.01$ & 175 & $+4.4 \times 10^{15}$ & 8 \\
$\mathrm{SnS}(1 \% \mathrm{Sb})$ & $99: 1$ & $0.7 \pm 0.2$ & $4.30 \pm 0.01$ & $11.19 \pm 0.02$ & $3.99 \pm 0.01$ & $3.82 \times 10^{4}$ & below measurement \\
$\mathrm{SnS}(2 \% \mathrm{Sb})$ & $49: 1$ & $1.2 \pm 0.3$ & $4.27 \pm 0.01$ & $11.17 \pm 0.02$ & $3.99 \pm 0.01$ & $3.74 \times 10^{4}$ & sensitivity \\
$\mathrm{SnS}(5 \% \mathrm{Sb})$ & $19: 1$ & $4.5 \pm 0.3$ & $4.28 \pm 0.01$ & $11.19 \pm 0.02$ & $3.99 \pm 0.01$ & $1.60 \times 10^{4}$ & \\
\hline
\end{tabular}
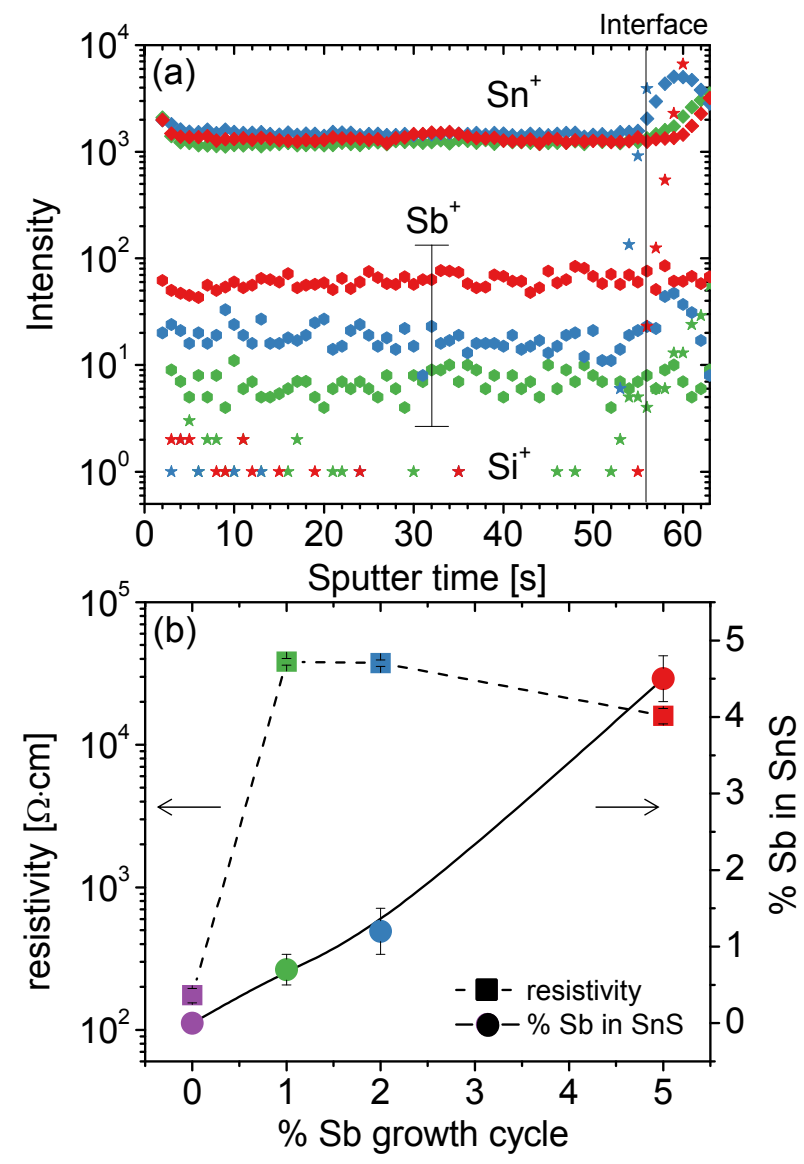

Figure 2. (a) ToF-SIMS of Sb-doped SnS films at 1\%, 2\%, and 5\% $\mathrm{Sb}$ growth cycle. (b) Film resistivity and $\mathrm{Sb}$ concentration in $\mathrm{SnS}$ determined from ToF-SIMS as a function of the \% Sb growth cycle.

From Figure 2b, a slight deviation from linearity between the $\mathrm{Sb}$ concentration and $\mathrm{Sb}$ growth cycle percentage was observed in the $\mathrm{SnS}(5 \% \mathrm{Sb})$ sample. If the reactivity of $\mathrm{Sb}(\mathrm{III})$ precursor and $\mathrm{H}_{2} \mathrm{~S}$ was identical on $\mathrm{SnS}$ and $\mathrm{SnS}(\mathrm{x} \% \mathrm{Sb}$ ) surfaces, then the atomic concentrations of $\mathrm{Sb}$ would be linearly proportional to their respective cycle percentages. However, the reactivities and chemisorptions on different surfaces, in general, are not the same. Thus, the actual Sb concentrations may not be exactly proportional to the cycle ratios, as observed in this case. This phenomenon was also observed in other doping systems, such as $\mathrm{Al}$ doped into $\mathrm{ZnO},{ }^{24} \mathrm{TiO}_{2},{ }^{25}$ and $\mathrm{SnO}_{2}$. ${ }^{26}$

Figure 3a shows the X-ray diffraction (XRD) patterns of SnS and Sb-doped SnS films, which correspond to the orthorh-
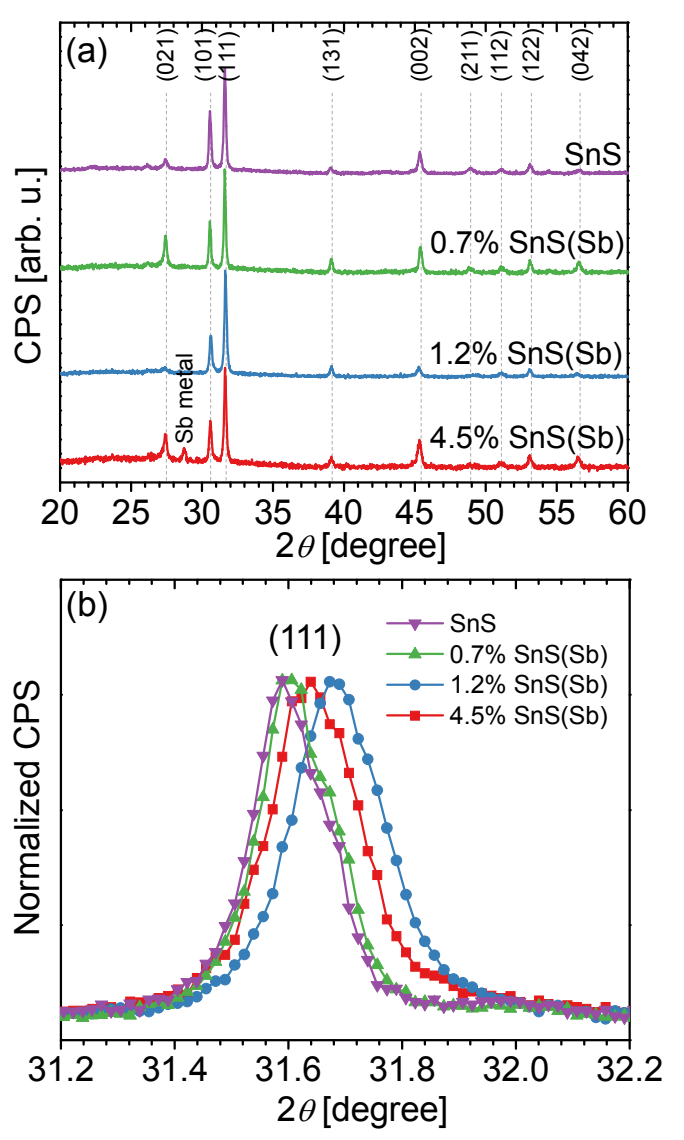

Figure 3. (a) XRD spectra of $\mathrm{SnS}$ and $0.7 \%, 1.2 \%$, and $4.5 \% \mathrm{Sb}$ doped SnS. (b) An expansion around (111) lattice plane showing changes in lattice constants after Sb-doping.

ombic structure of Herzenbergite SnS (PDF No. 00-039-0354, a $=4.3291 \AA, b=11.1923 \AA, c=3.9838 \AA)$. Other impurity phases (i.e., $\mathrm{Sn}_{2} \mathrm{~S}_{3}$ and $\mathrm{SnS}_{2}$ ) were not detected in the deposited films. At $4.5 \%$ Sb-concentration, one Bragg peak at $2 \theta=28.7^{\circ}$ was observed, but this peak does not belong to the known $\mathrm{SnS}$ or $\mathrm{Sb}_{2} \mathrm{~S}_{3}$ phases. The peak could be assigned to the (040) plane of Valentinite $\mathrm{Sb}_{2} \mathrm{O}_{3}$ (PDF No. 01-072-2738) or the (012) plane of rhombohedral Sb (PDF No. 00-035-0732). However, depth profiling XPS reveals no oxygen contamination in this sample. Thus, this Bragg peak is most likely due to Sb; presumably, the concentration of $\mathrm{Sb}$ in this sample exceeded the solid solubility at deposition temperature (or upon cooling); the resulting supersaturation was relieved via precipitation of a secondary 
Table 2. Path names for each structure model with corresponding half-path lengths and coordination numbers. All paths are single-scattering events with $\mathrm{Sb}$ as the atom of origin. For model (b), the atom of origin is shown in brackets to distinguish between the two distinct lattice sites of $\mathrm{Sb}$ in $\mathrm{Sb}_{2} \mathrm{~S}_{3}$, denoted by $\mathrm{Sb}_{1}$ and $\mathrm{Sb}_{2}$.

\begin{tabular}{|c|c|c|c|c|c|c|c|c|}
\hline \multicolumn{9}{|c|}{ Structure model } \\
\hline \multicolumn{3}{|c|}{$\mathrm{SnS}\left(\mathrm{Sb}_{\mathrm{Sn}}\right)^{(\mathrm{a})}$} & \multicolumn{3}{|c|}{$\mathrm{Sb}_{2} \mathrm{~S}_{3}{ }^{(\mathrm{b})}$} & \multicolumn{3}{|c|}{ Sb metal ${ }^{(c)}$} \\
\hline Path & $R_{\text {eff }}(\AA)$ & $N$ & Path & $R_{\text {eff }}(\AA)$ & $N$ & Path & $R_{\text {eff }}(\AA)$ & N \\
\hline $\mathrm{S}_{1}$ & 2.6237 & 1 & {$\left[\mathrm{Sb}_{1}\right]-\mathrm{S}_{3}$} & 2.5044 & 1 & $\mathrm{Sb}_{2}$ & 2.9063 & 3 \\
\hline $\mathrm{S}_{2}$ & 2.6658 & 2 & {$\left[\mathrm{Sb}_{1}\right]-\mathrm{S}_{2}$} & 2.5225 & 2 & $\mathrm{Sb}_{3}$ & 3.3513 & 3 \\
\hline $\mathrm{S}_{3}$ & 3.2908 & 2 & {$\left[\mathrm{Sb}_{2}\right]-\mathrm{S}_{1}$} & 2.3836 & 1 & - & - & - \\
\hline $\mathrm{S}_{4}$ & 3.3908 & 1 & {$\left[\mathrm{Sb}_{2}\right]-\mathrm{S}_{3}$} & 2.6747 & 2 & - & - & - \\
\hline $\mathrm{Sn}_{1}$ & 3.4937 & 2 & - & - & - & - & - & - \\
\hline $\mathrm{Sn}_{2}$ & 3.9870 & 2 & - & - & - & - & - & - \\
\hline
\end{tabular}

phase. Figure $3 \mathrm{~b}$ presents the XRD in the region near the (111) lattice plane. Since Bragg angle $\theta$ is inversely proportional to the lattice spacing $d$, which for (111) plane equals to $[a b c]\left[(a b)^{2}+(b c)^{2}+(a c)^{2}\right]^{-1 / 2}$ where $a, b$, and $c$ are lattice constants, the shift of the (111) peak position to the higher $\theta$ value indicates the crystal lattice shrinkage after Sb-doping. This unit cell volume decreases with increasing $\mathrm{Sb}$ concentration from 0.7\% to $1.2 \%$ probably due to substitution of smaller $\mathrm{Sb}^{3+}$ for $\mathrm{Sn}^{2+}$, but increases less with higher (4.5\%) doping because of the precipitation of the secondary phase, as we shall see by correlating these results with EXAFS.

Table 1 shows some electrical properties of SnS and Sbdoped SnS thin films at $300 \mathrm{~K}$. The undoped SnS thin film shows resistivity of $175 \Omega \mathrm{cm}$, hole concentration of $4.4 \times 10^{15}$ $\mathrm{cm}^{-3}$, and mobility of $8 \mathrm{~cm}^{2} \mathrm{~V}^{-1} \mathrm{~s}^{-1}$. The addition of small amounts of $\mathrm{Sb}$, even at $0.7 \%$ concentration, effectively produces an insulating film with resistivity increased to $3.82 \times 10^{4} \Omega \mathrm{cm}$, more than two orders of magnitude higher than the undoped film. Upon increasing Sb concentration up to $1.2 \%$, the resistivity of Sb-doped SnS film remains roughly the same, $3.74 \times 10^{4} \Omega \mathrm{cm}$. However, the film resistivity drops by half to $1.60 \times 10^{4} \Omega \mathrm{cm}$ when the $\mathrm{Sb}$ concentration increases up to $4.5 \%$. Unfortunate$\mathrm{ly}$, the carrier concentration and conductivity type of the Sbdoped SnS films cannot be measured from the current Hall setup because of their high resistivities.

To clarify the mechanism behind the anomalous rise and fall of $\mathrm{SnS}$ film resistivity with increasing $\mathrm{Sb}$ doping concentration, we performed Extended X-ray Absorption Fine Structure (EXAFS) measurements at the Sb edge. The EXAFS technique is sensitive to the local atomic environment surrounding the dopant atoms, elucidating the chemical state of the dopant atoms (e.g., substitutional, interstitial, or second-phase particle). EXAFS was performed at the $\mathrm{Sb}-\mathrm{K}_{\alpha} \mathrm{X}$-ray absorption edge on the $1.2 \% \mathrm{SnS}(\mathrm{Sb})$ film, the $4.5 \% \mathrm{SnS}(\mathrm{Sb})$ film, the $\mathrm{Sb}_{2} \mathrm{~S}_{3}$ film, and an $\mathrm{Sb}$ metal reference standard. We also performed EXAFS on the $0.7 \% \mathrm{SnS}(\mathrm{Sb})$ film, but the signal was too weak to obtain a high-quality EXAFS spectrum. Data were analyzed using standard EXAFS analysis procedures ${ }^{27}$ to obtain the Fourier transforms of the EXAFS spectra shown in Figure 4. All spectra were $\mathrm{k}$-weighted by 1 , and the transform ranges for each of the spectra were 3.15-9, 3-10.6, 3.3-12.2, and 2.75-15 $\AA^{-1}$, respectively. In Fig. 4, the peak at $2 \AA$ of the $1.2 \% \mathrm{SnS}(\mathrm{Sb})$ Fourier transformed EXAFS spectrum matches well with that of the $\mathrm{Sb}_{2} \mathrm{~S}_{3}$ spectrum. In $\mathrm{Sb}_{2} \mathrm{~S}_{3}$, this peak is due to the sulfur nearest neigh- bors of antimony, suggesting that the antimony in the $1.2 \%$ $\mathrm{SnS}(\mathrm{Sb})$ sample may be incorporated into the film in a sulfur environment. In contrast, the Fourier transformed EXAFS spectrum of the $4.5 \% \mathrm{SnS}(\mathrm{Sb})$ shows close resemblance to that of $\mathrm{Sb}$ metal, implying that the antimony in the $4.5 \% \mathrm{SnS}(\mathrm{Sb})$ may be present in an antimony environment.

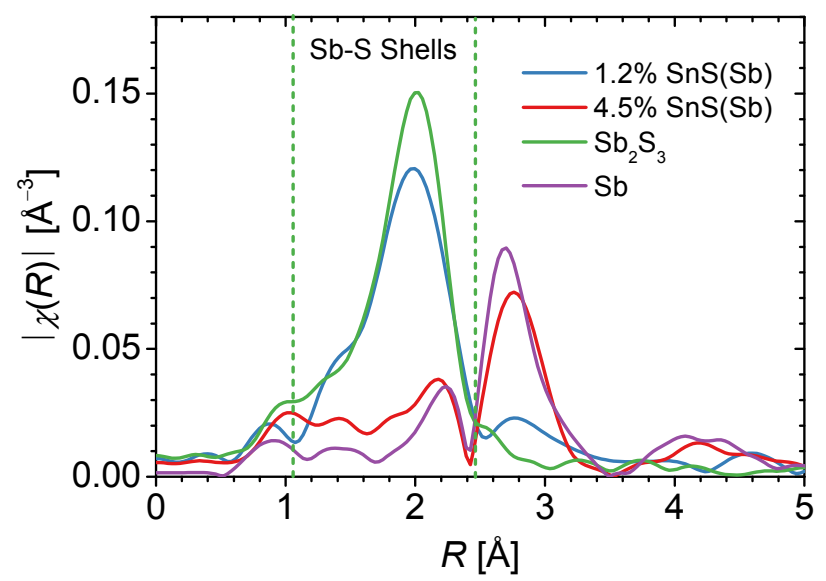

Figure 4. Summary of EXAFS measurements: The magnitude of the complex Fourier transform of $\chi(\mathrm{k})$ at the $\mathrm{Sb}$ edge of the $1.2 \%$ $\mathrm{SnS}(\mathrm{Sb})$ film, $4.5 \% \mathrm{SnS}(\mathrm{Sb})$ film, $\mathrm{Sb}_{2} \mathrm{~S}_{3}$ film, and $\mathrm{Sb}$ metal standard. The peak at $2 \AA$ in the $\mathrm{Sb}_{2} \mathrm{~S}_{3}$ data is due to sulfur nearestneighbors of antimony.

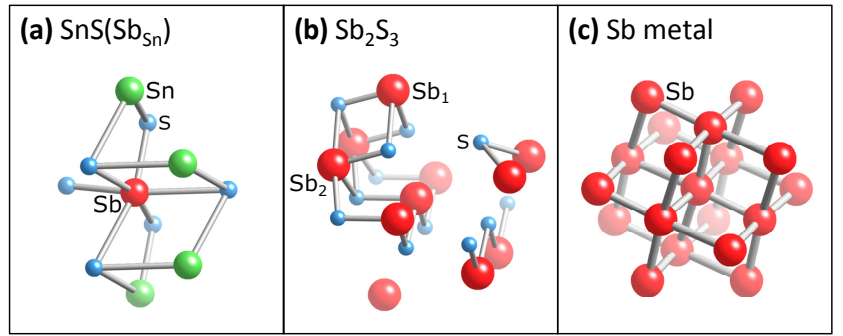

Figure 5. Ball-and-stick representation of (a) $\mathrm{SnS}$ with the $\mathrm{Sb}_{\mathrm{Sn}}$ substitution at the central atom, (b) $\mathrm{Sb}_{2} \mathrm{~S}_{3}$, and (c) Sb metal. Green: Sn; Blue: S; Red: Sb. For clarity, the cluster sizes shown are smaller than those used for EXAFS fitting. Note the two distinct lattice sites of $\mathrm{Sb}$ in $\mathrm{Sb}_{2} \mathrm{~S}_{3}$, the trivalent $\mathrm{Sb}_{1}$ and quintvalent $\mathrm{Sb}_{2}$. Nearestneighbor distances are given in Table 2. 


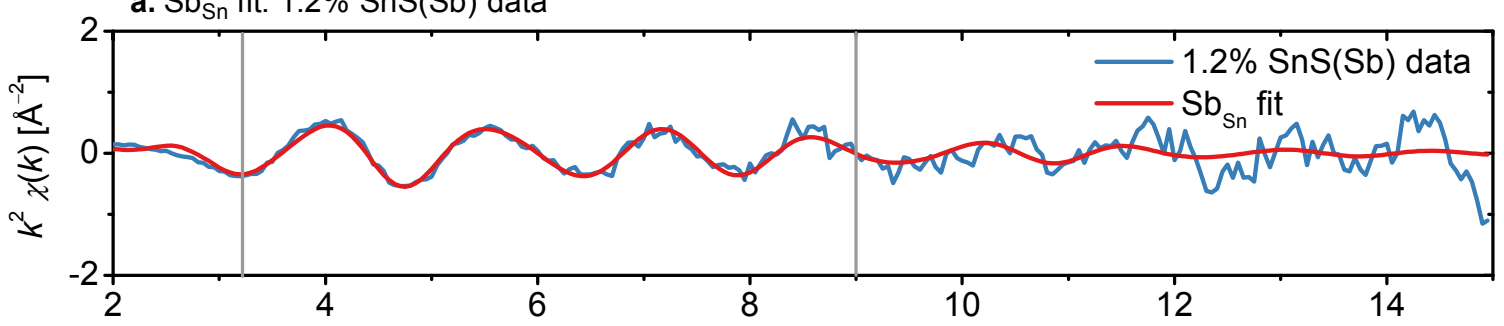

b. $\mathrm{Sb}_{2} \mathrm{~S}_{3}$ fit: $1.2 \% \mathrm{SnS}(\mathrm{Sb})$ data

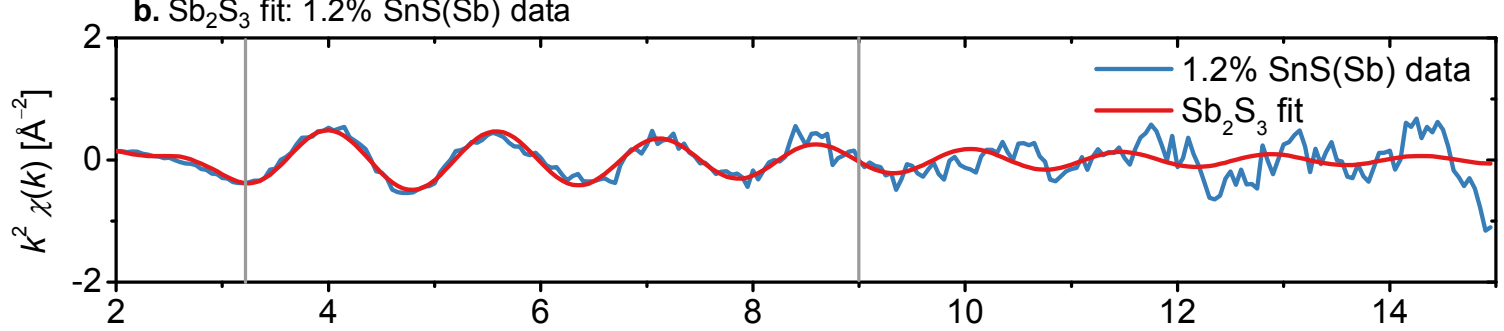

c. $\mathrm{Sb}$ metal fit: $4.5 \% \mathrm{SnS}(\mathrm{Sb})$ data

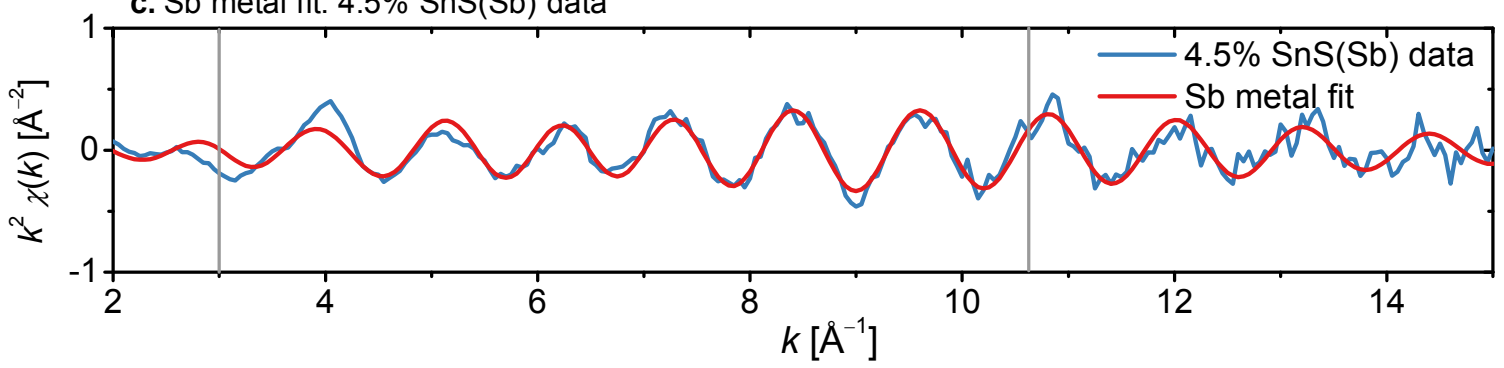

Figure 6. EXAFS data and fits for $\mathrm{Sb}$ edge: (a) $1.2 \% \mathrm{SnS}(\mathrm{Sb})$ data with $\mathrm{SnS}\left(\mathrm{Sb}_{\mathrm{Sn}}\right.$ ) fit, (b) $1.2 \% \mathrm{SnS}(\mathrm{Sb})$ data with $\mathrm{Sb}_{2} \mathrm{~S}_{3}$ fit, and (c) $4.5 \%$ $\mathrm{SnS}(\mathrm{Sb})$ data with $\mathrm{Sb}$ metal fit. The vertical lines denote the range chosen for Fourier transformation.

To elucidate the precise chemical states of Sb dopants in SnS films, EXAFS spectra were modeled using the Artemis interface to the IFEFFIT software package. ${ }^{28}$ In the $1.2 \% \mathrm{SnS}(\mathrm{Sb})$ film, antimony may either be incorporated into the film as an $\mathrm{Sb}_{\mathrm{Sn}}$ substitution as desired, or as $\mathrm{Sb}_{2} \mathrm{~S}_{3}$ second-phase particles. For this reason, we evaluated both structural models: (a) a 6-shell model of $\mathrm{SnS}$ with the $\mathrm{Sb}_{\mathrm{Sn}}$ substitution at the central atom, denoted by $\mathrm{SnS}\left(\mathrm{Sb}_{\mathrm{Sn}}\right)$; (b) a 4-shell model of $\mathrm{Sb}_{2} \mathrm{~S}_{3}$ with the two distinct lattice sites of $\mathrm{Sb}$ in $\mathrm{Sb}_{2} \mathrm{~S}_{3}$ weighted equally. For the $4.5 \% \mathrm{SnS}(\mathrm{Sb})$ film, we evaluated a 2 -shell model of $\mathrm{Sb}$ metal. Figure 5 gives a spatial representation of each structural model. The paths used in each model are outlined in Table 2. The refinements were performed using 6-10 free parameters, including the half-path lengths $\delta R_{i}$, their mean square variation $\sigma_{i}^{2}$, the relaxation term $S_{0}^{2}$, and energy offset $E_{0}$, with 8-12 independent points per dataset.

The refinements of models (a) and (b) achieved good fits $(R=$ $1.5 \%$ and $R=1.7 \%$, respectively) for the $1.2 \% \mathrm{SnS}(\mathrm{Sb})$ data, while the refinement of model (c) achieved a good fit $(R=$ $3.4 \%$ ) for the $4.5 \% \mathrm{SnS}(\mathrm{Sb})$ data. Figure 6 shows these EXAFS data and fits, and Figure 7 shows the real parts and magnitudes of the Fourier transform of these data. Table 3 gives the best-fit values of parameters for the fitted spectra. Attempts to refine model (c) for the $1.2 \% \mathrm{SnS}(\mathrm{Sb})$ data or models (a) and (b) for the $4.5 \% \mathrm{SnS}(\mathrm{Sb})$ data were not possible with $R$ values under $60 \%$. The $\mathrm{Sb}$ substitutional $\left[\mathrm{SnS}\left(\mathrm{Sb}_{\mathrm{S}_{\mathrm{n}}}\right)\right]$ model qualitatively gives the best fit for the $1.2 \% \mathrm{SnS}(\mathrm{Sb})$ data, closely matching the phase and amplitude of $\chi(R)$ beyond the sulfur shells. Although the $\mathrm{Sb}_{2} \mathrm{~S}_{3}$ model also fits reasonably well to the data, formation of the $\mathrm{Sb}_{2} \mathrm{~S}_{3}$ phase is unsupported by XRD of the $1.2 \% \mathrm{SnS}(\mathrm{Sb})$ film. Peaks corresponding to $\mathrm{Sb}_{2} \mathrm{~S}_{3}$ were not observed in the XRD pattern, and the SnS lattice constant shift indicates an incorporation of $\mathrm{Sb}$ into the $\mathrm{SnS}$ lattice. Furthermore, the phase composition of the SnS-Sb system as measured by Kurbanova et al. includes only the $\mathrm{SnS}$ and $\mathrm{Sb}$ phases for temperatures of $30-500{ }^{\circ} \mathrm{C} \cdot{ }^{29}$ For these reasons, we believe that antimony is predominantly acting as a substitutional dopant in the $1.2 \% \mathrm{SnS}(\mathrm{Sb})$, causing the observed increase in resistivity. However, we cannot rule out the possibility that a small fraction of $\mathrm{Sb}$ exists in the $\mathrm{Sb}_{2} \mathrm{~S}_{3}$ phase, falling below the sensitivity of XRD.

The Sb metal model matches well with the $4.5 \% \mathrm{SnS}(\mathrm{Sb})$ EXAFS data. This supports our hypothesis that the antimony in the $4.5 \% \mathrm{SnS}(\mathrm{Sb})$ is present predominantly in a secondary phase, consistent both with our XRD observation of a new peak emerging with high doping density, and with the aforementioned phase composition study of the SnS-Sb system. ${ }^{29}$ The formation of $\mathrm{Sb}$ metal observed by EXAFS may underlie the decrease of resistivity at the highest $\mathrm{Sb}$ doping level; since the majority of dopant atoms in this film do not occupy substitutional lattice sites, the degree of compensation is reduced, and the free hole concentration is increased. We also note that dopant precipitation into metallic nanoparticles has been observed for other systems such as metal-doped $\mathrm{ZnO}{ }^{30,31}$ 
Table 3. Best-fit EXAFS parameters and corresponding paths for three structure models. Models (a) and (b) are fit to $1.2 \% \mathrm{SnS}(\mathrm{Sb})$ data, and model (c) is fit to $4.5 \% \mathrm{SnS}(\mathrm{Sb})$ data. See Table 1 for path details

\begin{tabular}{|c|c|c|c|c|c|c|}
\hline \multirow{3}{*}{ Parameters } & \multicolumn{6}{|c|}{ Structure model } \\
\hline & \multicolumn{2}{|c|}{$\mathrm{SnS}\left(\mathrm{Sb}_{\mathrm{Sn}}\right)^{(\mathrm{a})}$} & \multicolumn{2}{|c|}{$\mathrm{Sb}_{2} \mathrm{~S}_{3}{ }^{(b)}$} & \multicolumn{2}{|c|}{$\mathrm{Sb}^{(c)}$} \\
\hline & Values & Path & Values & Path & Values & Path \\
\hline$E_{0}$ & $10.2(2.7)$ & All paths & $10.6(1.0)$ & All paths & $9.9(2.3)$ & All paths \\
\hline$S_{0}^{2}$ & $0.82(0.05)$ & All paths & $0.93(0.10)$ & All paths & $0.77(0.25)$ & All paths \\
\hline$\delta R_{1}$ & $-0.15(0.02)$ & $\mathrm{S}_{1}$ & $0.02(24.7)$ & {$\left[\mathrm{Sb}_{1}\right]-\mathrm{S}_{3}$} & $0.00069(0.017)$ & $\mathrm{Sb}_{2}$ \\
\hline$\delta R_{2}$ & $\delta R_{1}$ & $\mathrm{~S}_{2}$ & $0.0002(2.8)$ & {$\left[\mathrm{Sb}_{1}\right]-\mathrm{S}_{2}$} & $0.0032(0.060)$ & $\mathrm{Sb}_{3}$ \\
\hline$\delta R_{3}$ & $0.050(0.089)$ & $\mathrm{S}_{3}$ & $-0.01(0.07)$ & {$\left[\mathrm{Sb}_{2}\right]-\mathrm{S}_{1}$} & - & - \\
\hline$\delta R_{4}$ & $0.21(0.35)$ & $\mathrm{S}_{4}$ & $-0.16(0.36)$ & {$\left[\mathrm{Sb}_{2}\right]-\mathrm{S}_{3}$} & - & - \\
\hline$\delta R_{5}$ & $-0.08(0.11)$ & $\mathrm{Sn}_{1}$ & $\cdot$ & $\cdot$ & - & - \\
\hline$\delta R_{6}$ & $-0.26(0.13)$ & $\mathrm{Sn}_{2}$ & - & - & - & - \\
\hline$\sigma_{1}^{2}$ & $0.0052(0.0020)$ & $\mathrm{S}_{1}$ & 0.003 & {$\left[\mathrm{Sb}_{1}\right]-\mathrm{S}_{3}$} & $0.0051(0.0024)$ & $\mathrm{Sb}_{2}$ \\
\hline$\sigma_{2}^{2}$ & $\sigma_{1}^{2}$ & $\mathrm{~S}_{2}$ & $\sigma_{1}^{2}$ & {$\left[\mathrm{Sb}_{1}\right]-\mathrm{S}_{2}$} & $0.019(0.011)$ & $\mathrm{Sb}_{3}$ \\
\hline$\sigma_{3}^{2}$ & $0.011(0.022)$ & $\mathrm{S}_{3}$ & $0.0063(0.0072)$ & {$\left[\mathrm{Sb}_{2}\right]-\mathrm{S}_{1}$} & - & - \\
\hline$\sigma_{4}^{2}$ & $\sigma_{3}^{2}$ & $\mathrm{~S}_{4}$ & $0.0056(0.0031)$ & {$\left[\mathrm{Sb}_{2}\right]-\mathrm{S}_{3}$} & - & - \\
\hline$\sigma_{5}^{2}$ & $0.014(0.039)$ & $\mathrm{Sn}_{1}$ & - & - & - & - \\
\hline$\sigma_{6}^{2}$ & $\sigma_{5}^{2}$ & $\mathrm{Sn}_{2}$ & - & - & - & - \\
\hline
\end{tabular}
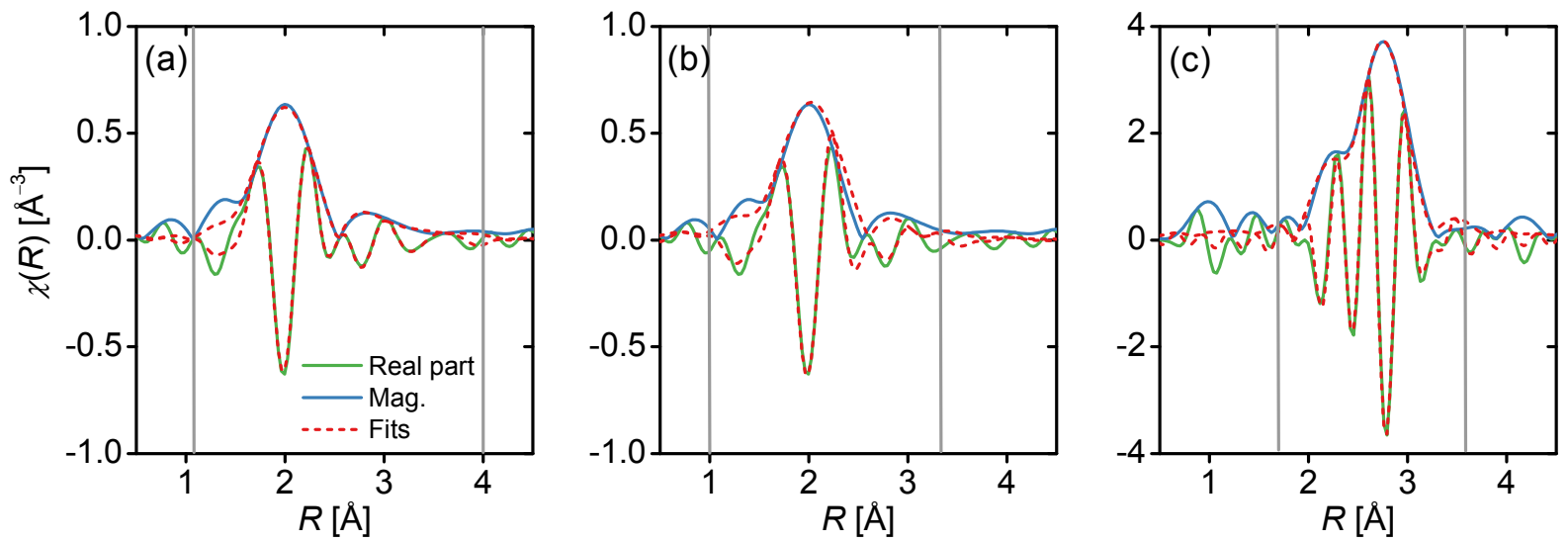

Figure 7. Real part and magnitude of Fourier transformed EXAFS data and fits: (a) $1.2 \% \mathrm{SnS}(\mathrm{Sb})$ data with $\mathrm{SnS}_{(\mathrm{Sb}} \mathrm{s}_{\mathrm{n}}$ ) fit, (b) $1.2 \%$ $\mathrm{SnS}(\mathrm{Sb})$ data with $\mathrm{Sb}_{2} \mathrm{~S}_{3}$ fit, and (c) $4.5 \% \mathrm{SnS}(\mathrm{Sb})$ data with $\mathrm{Sb}$ metal fit. The vertical lines denote the fitting range.

\section{Conclusion}

In conclusion, Sb-doped SbS thin films were deposited by pulsed-CVD using the reaction of $\mathrm{Sn}\left(\mathrm{MeC}(\mathrm{N}-i \mathrm{Pr})_{2}\right)_{2}$ and $\mathrm{Sb}\left(\mathrm{NMe}_{2}\right)_{3}$ with $\mathrm{H}_{2} \mathrm{~S}$. Small amounts of $\mathrm{Sb}(\sim 1 \%)$ in $\mathrm{SnS}$ increase the film resistivity by more than two orders of magnitude, most likely due to substitutional doping. Sb addition at low levels is an effective means of producing compensated, insulating SnS films, which could be useful in solar cells with a $p-i$ $n$ heterostructure. The conductivity type of the Sb-doped SnS films could not be determined because of their high resistivity. Increasing the doping level from $1.2 \%$ to $4.5 \%$ appears to cause clustering of the $\mathrm{Sb}$ into metallic precipitates.

\section{Corresponding Author}

*Tel: (617)-495-4017. Fax: (617)-495-4723. E-mail: gordon@chemistry.harvard.edu

\section{Acknowledgements}

We acknowledge Y. Segal for his contributions at the synchrotron beamline and his initial interpretations of the data. We also thank K. Hartman for her initial support in processing and analyzing the data. This work was supported by the U.S. Department of Energy SunShot Initiative under Contract No. DE-EE0005329, by the U.S. National Science Foundation under grant No. CBET-1032955, and by Saint Gobain S. A., which also supplied the SIMS analyses. P. Sinsermsuksakul appreciates the support from the Development and Promotion of Science and Technology Talents Project (DPST), Thailand. R. Chakraborty acknowledges the support of a National Science Foundation Graduate Research Fellowship. This work was performed in part at the Center for Nanoscale Systems (CNS), a member of the National Nanotechnology Infrastructure Network (NNIN), which is supported by the National Science Foundation under NSF award No. ECS-0335765. Use of the Advanced Photon Source, an Office of Science User Facility operated for the U.S. Department of Energy (DOE) 
Office of Science by Argonne National Laboratory, was supported by the U.S. DOE under Contract No. DE-AC02-06CH11357.

\section{References}

1. Wadia, C.; Alivisatos, A. P.; Kammen, D. M., Materials Availability Expands the Opportunity for Large-Scale Photovoltaics Deployment. Environmental Science $\mathcal{E}$ Technology 2009, 43, (6), 2072-2077.

2. Mathews, N. R.; Anaya, H. B. M.; Cortes-Jacome, M. A.; Angeles-Chavez, C.; Toledo-Antonio, J. A., Tin Sulfide Thin Films by Pulse Electrodeposition: Structural, Morphological, and Optical Properties. Journal of the Electrochemical Society 2010, 157, (3), H337-H341.

3. Sinsermsuksakul, P.; Heo, J.; Noh, W.; Hock, A. S.; Gordon, R. G., Atomic Layer Deposition of Tin Monosulfide Thin Films. Advanced Energy Materials 2011, 1, (6), 1116-1125.

4. Vidal, J.; Lany, S.; d'Avezac, M.; Zunger, A.; Zakutayev, A.; Francis, J.; Tate, J., Band-structure, optical properties, and defect physics of the photovoltaic semiconductor SnS. Applied Physics Letters 2012, 100, (3).

5. Ghosh, B.; Das, M.; Banerjee, P.; Das, S., Fabrication of the SnS/ZnO heterojunction for $\mathrm{PV}$ applications using electrodeposited $\mathrm{ZnO}$ films. Semiconductor Science and Technology 2009, 24, (2).

6. Reddy, K. T. R.; Reddy, N. K.; Miles, R. W., Photovoltaic properties of SnS based solar cells. Solar Energy Materials and Solar Cells 2006, 90, (18-19), $3041-3046$

7. Gunasekaran, M.; Ichimura, M., Photovoltaic cells based on pulsed electrochemically deposited SnS and photochemically deposited US and $\mathrm{Cd}_{1 \times \mathrm{x}} \mathrm{Zn}_{\mathrm{x}} \mathrm{S}$. Solar Energy Materials and Solar Cells 2007, 91, (9), 774-778.

8. Sanchez-Juarez, A.; Tiburcio-Silver, A.; Ortiz, A., Fabrication of $\mathrm{SnS}_{2} / \mathrm{SnS}$ heterojunction thin film diodes by plasma-enhanced chemical vapor deposition. Thin Solid Films 2005, 480, 452-456.

9. Wang, Y.; Gong, H.; Fan, B. H.; Hu, G. X., Photovoltaic Behavior of Nanocrystalline SnS/ $\mathrm{TiO}_{2}$. Journal of Physical Chemistry C 2010, 114, (7), 3256-3259

10. Jiang, F.; Shen, H. L.; Wang, W.; Zhang, L., Preparation of SnS Film by Sulfurization and $\mathrm{SnS} / a-\mathrm{Si}$ Heterojunction Solar Cells. Journal of the Electrochemical Society 2012, 159, (3), H235-H238.

11. Sugiyama, M.; Reddy, K. T. R.; Revathi, N.; Shimamoto, Y.; Murata, Y., Band offset of SnS solar cell structure measured by X-ray photoelectron spectroscopy. Thin Solid Films 2011, 519, (21), 7429-7431.

12. Sites, J.; Pan, J., Strategies to increase CdTe solar-cell voltage. Thin Solid Films 2007, 515, (15), 6099-6102.

13. Albers, W.; Vink, H. J.; Haas, C.; Wasscher, J. D., Investigations on Sns. Journal of Applied Physics 1961, 32, 2220-\&.

14. Devika, M.; Reddy, N. K.; Ramesh, K.; Gunasekhar, K. R.; Gopal, E. S. R.; Reddy, K. T. R., Low resistive micrometer-thick SnS : Ag films for optoelectronic applications. Journal of the Electrochemical Society 2006, 153, (8), G727-G733.

15. Zhang, S. A.; Cheng, S. Y., Thermally evaporated SnS:Cu thin films for solar cells. Micro $\mathcal{E}$ Nano Letters 2011, 6, (7), 559-562.

16. Dussan, A.; Mesa, F.; Gordillo, G., Effect of substitution of Sn for Bi on structural and electrical transport properties of SnS thin films. Journal of Materials Science 2010, 45, (9), 2403-2407.
17. Sajeesh, T. H.; Warrier, A. R.; Kartha, C. S.; Vijayakumar, K. P., Optimization of parameters of chemical spray pyrolysis technique to get $n$ and p-type layers of SnS. Thin Solid Films 2010, 518, (15), 4370-4374.

18. Hydrogen Sulfide; MSDS No.001029;. In Airgas Inc: Radnor, PA. April 26, 2010.

19. Dasgupta, N. P.; Mack, J. F.; Langston, M. C.; Bousetta, A.; Prinz, F. B. Design of an atomic layer deposition reactor for hydrogen sulfide compatibility. Review of Scientific Instruments 2010, 81, (4).

20. Yang, R. B.; Bachmann, J.; Reiche, M.; Gerlach, J. W.; Gosele, U.; Nielsch, K., Atomic Layer Deposition of Antimony Oxide and Antimony Sulfide. Chemistry of Materials 2009, 21, (13), 2586-2588.

21. Karuturi, S. K.; Liu, L. J.; Su, L. T.; Zhao, Y.; Fan, H. J.; Ge, X. C.; He, S. L.; Yoong, A. T. I., Kinetics of Stop-Flow Atomic Layer Deposition for High Aspect Ratio Template Filling through Photonic Band Gap Measurements. Journal of Physical Chemistry C 2010, 114, (35), 14843-14848. 22. Heo, J.; Hock, A. S.; Gordon, R. G., Low Temperature Atomic Layer Deposition of Tin Oxide. Chemistry of Materials 2010, 22, (17), 4964-4973.

23. Heald, S.; Stern, E.; Brewe, D.; Gordon, R.; Crozier, D.; Jiang, D. T.; Cross, J., XAFS at the Pacific Northwest Consortium-Collaborative Access Team undulator beamline. Journal of Synchrotron Radiation 2001, 8, 342-344. 24. Na, J. S.; Peng, Q.; Scarel, G.; Parsons, G. N., Role of Gas Doping Sequence in Surface Reactions and Dopant Incorporation during Atomic Layer Deposition of Al-Doped ZnO. Chemistry of Materials 2009, 21, (23), 5585-5593.

25. Kim, S. K.; Choi, G. J.; Kim, J. H.; Hwang, C. S., Growth behavior of Al-doped $\mathrm{TiO}_{2}$ thin films by atomic layer deposition. Chemistry of Materials 2008, 20, (11), 3723-3727.

26. Heo, J.; Liu, Y. Q.; Sinsermsuksakul, P.; Li, Z. F.; Sun, L. Z.; Noh, W.; Gordon, R. G., $(\mathrm{Sn}, \mathrm{Al}) \mathrm{O}_{\mathrm{x}}$ Films Grown by Atomic Layer Deposition. Journal of Physical Chemistry C 2011, 115, (20), 10277-10283.

27. Sayers, D. E.; Bunker, B. A., X-Ray Absorption: Basic Principles of EXAFS, SEXAFS and XANES. In Koningsberger, D. C.; Prin, R., Eds. Wiley: New York, 1988; p 211.

28. Ravel, B.; Newville, M., ATHENA, ARTEMIS, HEPHAESTUS: data analysis for X-ray absorption spectroscopy using IFEFFIT. Journal of Synchrotron Radiation 2005, 12, 537-541.

29. Kurbanova, R. D.; Movsumzade, A. A.; Allazov, M. R., The SnS-Sb System. Inorganic Materials 1987, 23, (11), 1585-1587.

30. Heald, S. M.; Kaspar, T.; Droubay, T.; Shutthanandan, V.; Chambers, S.; Mokhtari, A.; Behan, A. J.; Blythe, H. J.; Neal, J. R.; Fox, A. M.; Gehring, G. A., X-ray absorption fine structure and magnetization characterization of the metallic Co component in Co-doped $\mathrm{ZnO}$ thin films. Physical Review B 2009, 79, (7)

31. Fons, P.; Yamada, A.; Iwata, K.; Matsubara, K.; Niki, S.; Nakahara, K.; Takasu, H., An EXAFS and XANES study of MBE grown Cu-doped ZnO. Nuclear Instruments $\mathcal{E}$ Methods in Physics Research Section B-Beam Interactions with Materials and Atoms 2003, 199, 190-194. 
Table of Contents Graphic.
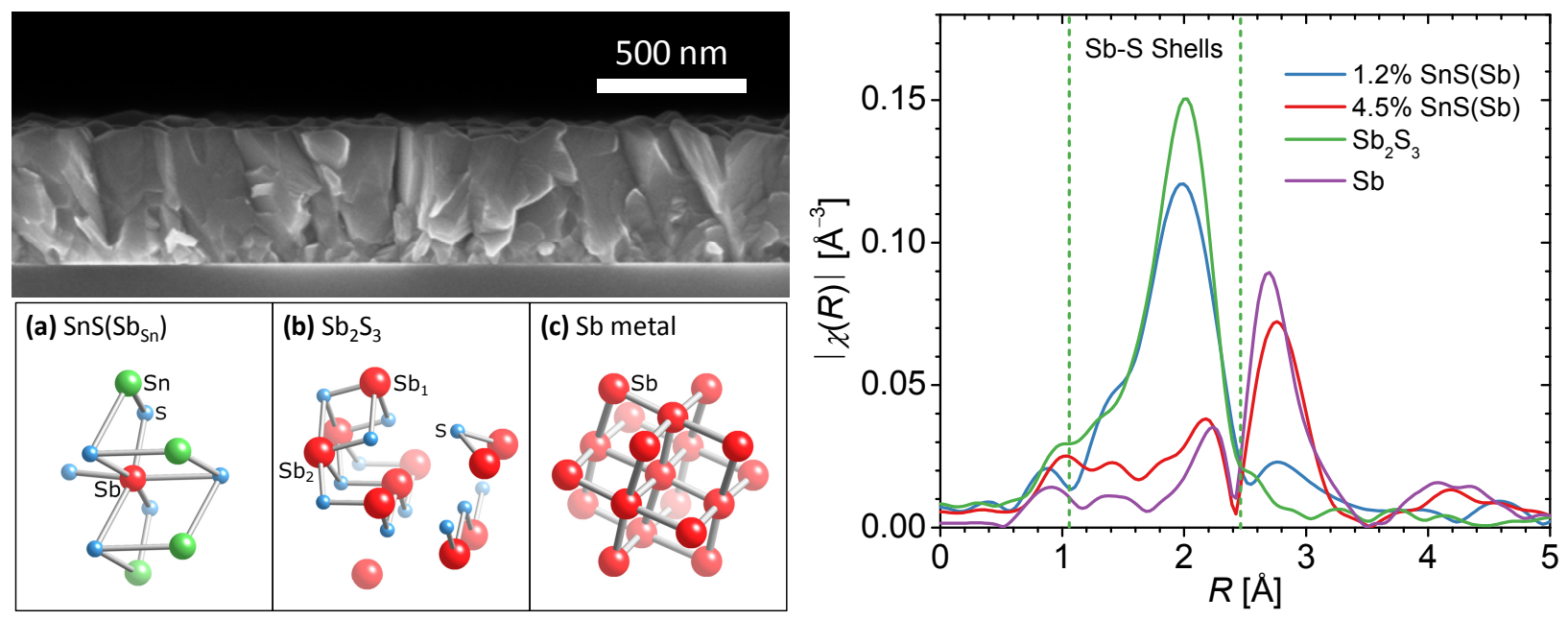